\title{
Sliding Mode Observer based sensorless control of five phase PMSM in electric vehicle
}

\author{
Abir Hezzi \\ MACS LR16ES22 \\ University of Gabes \\ Email: abir.hezzi@gmail.com \\ Mohamed Naceur Abdelkrim \\ MACS LR16ES22 \\ University of Gabes \\ Email: naceur.abdelkrim@laposte.net
}

\author{
Yemna Bensalem \\ MACS LR16ES22 \\ University of Gabes \\ Email: bensalem.yemna2017@gmail.com
}

\author{
Seifeddine Ben Elghali \\ LIS UMR CNRS 7020 \\ University of Aix-Marseille, \\ Email: seifeddine.benelghali@lis-lab.fr
}

\begin{abstract}
The impact of the third order current harmonic cannot be ignored in a five-phase permanent magnet synchronous motor (PMSM), on the contrary of the three-phase PMSM. So, to realize the speed sensorless control for PMSM, a Sliding Mode Observer (SMO) is suggested with consideration the impact of third order harmonic. At the outset, a Sliding Mode Control (SMC) with injection of the third order current harmonic is designed for speed sensorless control of PMSM model for Electric Vehicle (EV). Then, Sliding Mode Observer is built to estimate the motor speed, torque and current in $(d, q)$ frame, in order to improve the performance of sensorless control strategy. Besides, the stability of the SMC and SMO are studied using Lyapunov stability criteria. The feasibility of this technique will be evaluated using MATLAB/Simulink platform

Index Terms-Five phase PMSM, Third order current harmonic, Sliding Mode Control, Sliding Mode Observer, electric vehicle.
\end{abstract}

\section{INTRODUCTION}

Due to the advancement of the power electronics technology, the poly-phase permanent magnet synchronous motor (PMSM) has become increasingly attractive. It guarantees a lot of performances, as high torque and low inertia, high efficiency, and elevated speed. In addition to its ability to reduce the stator current per phase without increasing the stator voltage, and achieving minimum torque ripple with lower vibration. It is able to carry operation even with loss of supply of one or more than one phase. This confirms the high fault tolerance of multi-phase machines [1]. They also present other advantages, which are redundant, reliable and an additional degree of freedom [2]. Thanks to its attractive properties, poly-phase machine has been used in several applications, [3], where high performance and reliability are demanded. For instance, in the case of an electric vehicle. For that reason, most electric vehicle development company prefers vector control strategy to drive the multi-phase PMSM, [4], [5]. This strategy needs the knowledge of speed and rotor position, so they need to use position and speed sensors, which makes the multi-phase PMSM drive less reliable and more expensive, because of their sensitivity to the environmental constraints as temperature and vibration [6].
Many researchers, in literature, have been analysis the concept of sensorless control strategy for multi-phase PMSM such as Kalman filtering [7], interval observer [8], and Sliding mode observer [9].

To overcome these drawbacks, a lot of researchers used a sensorless sliding mode control, which is defined as the simplest control technique to implement, even for nonlinear systems. This control strategy provides many advantages such as robustness and better transient performance, [10]. The essential idea of the sliding mode control is to drive the trajectory of the system state close to sliding surface. On time sliding surface is reached, the trajectory of system slides around it, and the system becomes robust against external parametric variations and disturbances. Actually, sliding mode theory proved its worth in control and estimation schemes. The design of sliding mode observers had an important discussion in many research works, [11], [10]. The developed SMO replaces the traditional switch function with a saturation function in order to reduce chattering phenomenon, and improve accuracy of parameters estimation.

In this work, a proposed sliding mode observer based sensorless control strategy to drive the five phase PMSM for electric vehicles. This paper is ordered as follows. In section II, a vehicle dynamics modelling is described. In section III a sliding mode control is designed with third current harmonic injected.SMO is presented in section IV, with system description and stability analysis.Section V deals with robustness study and simulation results, and section VI is concerned to the conclusion

\section{VEHICLE DYNAMICS MODELLING}

Based on aerodynamics and vehicle mechanics principles, [2], [12], the road load of an EV can be described by:

$$
F_{T}=F_{r}+F_{\text {aero }}+F_{g}+F_{a c c}
$$

where $F_{r}$ is the rolling resistance force produced by the tire flattening. $F_{\text {aero }}$ is the viscous resistance called the aerody- 
namic drag. $F_{g}$ is the grading resistance force, and $F_{a c c}$ is the acceleration force. The load torque $T_{L}$ of an EV is given by:

$$
T_{L}=\frac{r}{i} F_{T}=\frac{T_{L_{-} \text {wheel }}}{i}
$$

where $r$ is the dynamic radius of tire, $i$ is the transmission ratio and $T_{L_{-} \text {wheel }}$ is the load torque of wheel. The power needed to drive a EV has to compensate the road load. It's described by:

$$
P_{T}=v F_{T}
$$

with $v$ is the vehicle speed which is dependant on motor speed , the tire radius and transmission ratio. In order that the vehicle speed reaches its descriptive value, it is necessary to lead the motor speed to achieve its reference value.

Usually,the feedback control of PMSM needs the precision value of the real speed which is dependant on electromagnetic and load torque.In this case, the forces that are acting on the electric vehicle affect the speed. Consequently, it is essential to produce the demanded torque to track the real speed to its reference value. Then, this work aiming for sensorless control of PMSM during different drive cycles to ensure EV operation.

\section{Sliding Mode Control of FIVE Phase PMSM}

\section{A. Five phase PMSM model}

The electrical equations of five-phase PMSM model in (d,q) frame are given by, [2]:

$$
\left\{\begin{array}{l}
V_{d p}=R i_{d p}+L_{p} \frac{d i_{d p}}{d t}-n_{p} \Omega L_{p} i_{q p} \\
V_{q p}=R i_{q p}+L_{p} \frac{d i_{q p}}{d t}+n_{p} \Omega L_{p} i_{d p}+\sqrt{\frac{5}{2}} k_{1} \Omega \\
V_{d s}=R i_{d s}+L_{s} \frac{d i_{d s}}{d t}-3 n_{p} \Omega L_{s} i_{q s} \\
V_{q s}=R i_{q s}+L_{s} \frac{d i_{q s}}{d t}+3 n_{p} \Omega L_{s} i_{d s}-\sqrt{\frac{5}{2}} k_{3} \Omega
\end{array}\right.
$$

Where $v_{d p}, v_{q p}, v_{d s}, v_{q s}, i_{d p}, i_{q p}, i_{d s}$ and $i_{q s}$ are respectively the stator voltages and currents The mechanical equations of PMSM in rotating frame are given by:

$$
\begin{gathered}
J \frac{d \Omega}{d t}=T_{e m}-f \Omega-T_{L} \\
T_{e m}=\sqrt{\frac{5}{2}}\left(k_{1} i_{q p}-k_{3} i_{q s}\right)
\end{gathered}
$$

where $T_{e m}, f$ and $T_{L}$ are electromagnetic torque, friction coefficient and unknown load torque, respectively.

\section{B. Optimum third order current harmonic}

Without harmonic components, the back electromotive force (EMF) is not sinusoidal waveform, for the most of PMSM manufactured.

The third current harmonic component is ordinarily the utmost dominant, then $k_{3}$ is different to zero, which improve the torque performance of the five phase PMSM. Based on the torque equation (6), this current will be derived. In steady state, electromagnetic torque is the objective torque to be produced and it was equal to the load torque.

$$
T_{e m}=T^{*}
$$

Using the torque reference, current $i_{q p}$ can be derived :

$$
i_{q p}=\frac{T^{*}-\sqrt{5 / 2} k_{3} i_{q s}}{\sqrt{5 / 2} k_{1}}
$$

Minimizing RMS phase currents, is one of the most performed conceptions of motor drive:

$$
\operatorname{Min}(I)=\operatorname{Min}\left(\sqrt{i_{q p}^{2}+i_{q s}^{2}}\right)
$$

Substituting (8) into (9), we can deduce:

$$
i_{q s}^{*}=\sqrt{\frac{2}{5}} \frac{T^{*} k_{3}}{k_{1}^{2}+k_{3}^{2}}
$$

Then, the fundamental current component is expressed by:

$$
i_{q p}^{*}=\sqrt{\frac{2}{5}} \frac{T^{*} k_{1}}{k_{1}^{2}+k_{3}^{2}}
$$

With the optimum third current harmonic injected, the motor can run smoother and the torque ripple will be reduced. The detailed analysis is available in [13]

\section{Sliding Mode Control}

SMC presents an impressive properties of robustness, accuracy, and easy implementation and tuning. The SMC is benefited by the ability of its dynamic behaviour of the system to conform by the particular choice of the sliding function, also its closed loop response becomes absolutely insensitive to some kind of uncertainties.

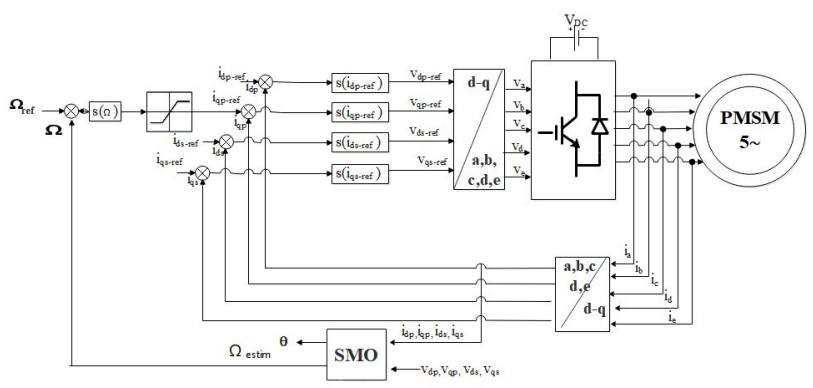

Fig. 1. Bloc diagram of SMC with SMO for five-phase PMSM..

Fig. 1. represents the speed sensorless control of five phase PMSM. The construction of SMC requires mainly three steps: beginning with the switching surface choice, then convergence condition, run out to control calculation

J. Slotine suggest a form of scalar function to determine the sliding surface [14]

$$
s(x, t)=\left(\frac{d}{d t}+\lambda\right)^{r-1} e(t)
$$

where $\lambda$ is a positive coefficient, $r$ is the relative degree, and $e(t)$ is the error given by:

$$
e(t)=x_{r e f}(t)-x(t)
$$

The convergence condition is defined by Lyapunov inequality:

$$
s(x) \dot{s}(x)<0
$$


Then the control algorithm comprises two terms, one concerning the exact linearization and an other stabilizing.

$$
u_{r e f}=u_{n}+u_{e q}
$$

$u_{e q}$ is calculated using the following expression: $\dot{s}(x)=0$ $u_{n}$ is described by $u_{n}=k \operatorname{sign}(x) ; k>0$

The first step of the SMC calculation for a PMSM is to describe the sliding surface, as:

$$
\left\{\begin{array}{l}
s(\Omega)=\Omega_{\text {ref }}-\Omega \\
s\left(i_{d p}\right)=i_{d p_{-} r e f}-i_{d p} \\
s\left(i_{q p}\right)=i_{q p_{-} r e f}-i_{q p} \\
s\left(i_{d s}\right)=i_{d s_{-} r e f}-i_{d s} \\
s\left(i_{q s}\right)=i_{q s_{-} r e f}-i_{q s}
\end{array}\right.
$$

Once the system reaches the sliding surface $s(\Omega)$ becomes equal to zero:

$$
\dot{s}(\Omega)=\frac{d \Omega_{r e f}}{d t}-\frac{d \Omega}{d t}=-\frac{d \Omega}{d t}=0
$$

then

$$
T_{\text {em }}=f \Omega+T_{L}
$$

From (5) and (11), $i_{q p \_r e f}$ can be expressed by:

$$
i_{q p \_r e f}=i_{q p \_e q}+i_{q p \_n}=\sqrt{\frac{2}{5}} \frac{T^{*} k_{1}}{k_{1}^{2}+k_{3}^{2}}+k_{\Omega} \operatorname{sign}(s(\Omega))
$$

The reference voltages can be written:

$$
\left\{\begin{array}{l}
v_{d p_{-} r e f}=R i_{d p}-n_{p} L_{p} \Omega i_{q p}+k_{d p} \operatorname{sign}\left(s\left(i_{d p}\right)\right) \\
v_{q p_{-} r e f}=R i_{q p}+n_{p} L_{p} \Omega i_{d p}+\sqrt{\frac{5}{2}} k_{1} \Omega+k_{q p} \operatorname{sign}\left(s\left(i_{q p}\right)\right) \\
v_{d s_{-} r e f}=R i_{d s}-3 n_{p} L_{s} \Omega i_{q s}+k_{d s} \operatorname{sign}\left(s\left(i_{d s}\right)\right) \\
v_{q s_{-} r e f}=R i_{q s}+3 n_{p} L_{s} \Omega i_{d s}-\sqrt{\frac{5}{2}} k_{3} \Omega+k_{q s} \operatorname{sign}\left(s\left(i_{q s}\right)\right)
\end{array}\right.
$$

The existence conditions of the sliding mode are [15]:

$$
\left\{\begin{array}{l}
k_{\Omega} \geq\left|f \Omega+T_{L} / \sqrt{\frac{5}{2}} k_{1}\right| \\
k_{d p} \geq\left|R i_{d p}-n_{p} L_{p} \Omega i_{q p}\right| \\
k_{q p} \geq\left|R i_{q p}+n_{p} L_{p} \Omega i_{d p}+\sqrt{\frac{5}{2}} k_{1} \Omega\right| \\
k_{d s} \geq\left|R i_{d s}-3 n_{p} L_{s} \Omega i_{q s}\right| \\
k_{q s} \geq\left|R i_{q s}+3 n_{p} L_{s} \Omega i_{d s}-\sqrt{\frac{5}{2}} k_{3} \Omega\right|
\end{array}\right.
$$

The high frequency oscillation phenomenon can be decreased by replacing the function 'sign' by a saturation function 'sat'. In order to realize the control system with high reliability, stability and accuracy, we need to evaluate the speed and torque value for the PMSM.

It can be noted that currents and back EMF contain the speed information as well as the electromagnetic torque.

\section{Sliding Mode Observer}

The SMO is one of the most used technique for speed sensorless control. This observer is aimed to estimate currents and back-EMF values, therefore, to valuate the torque, position and especially the rotor speed.This technique is detailed in
[16] and [17]. In the most cases currents and back-EMF are estimated in $(\alpha, \beta)$ frame, using the low pass filter as a simple solution to reduce noise, but this solution can cause severe phase lag. In this case the best idea is to estimate all parameters in $(\mathrm{d}, \mathrm{q})$ frame, without the use of filters.

\section{A. Current Observer}

SMO design is built on system variable structure theory. The currents are measurable parameters, and considered as output of the system. By using a mathematical model of PMSM in the rotating frame, the conventional SMO can be constructed as follows:

$$
\left\{\begin{array}{l}
L_{p} \frac{d \widehat{i_{d p}}}{d t}=-R \widehat{i_{d p}}+V_{d p}-K_{p} \operatorname{sign}\left(S_{d p}\right) \\
L_{p} \frac{d i_{q p}}{d t}=-R \widehat{i_{q p}}+V_{q p}-K_{p} \operatorname{sign}\left(S_{q p}\right) \\
L_{s} \frac{d i_{d s}}{d t}=-R \widehat{i_{d s}}+V_{d s}-K_{s} \operatorname{sign}\left(S_{d s}\right) \\
L_{s} \frac{d \hat{i_{q s}}}{d t}=-R \widehat{i_{q s}}+V_{q s}-K_{s} \operatorname{sign}\left(S_{q s}\right)
\end{array}\right.
$$

The sliding surface $\mathrm{S}(\mathrm{x})$ is expressed by:

$S(x)=\widehat{i}(t)-i(t)=0$

where $S(x)=\left[\begin{array}{llll}S_{d p} & S_{q p} & S_{d s} & S_{q s}\end{array}\right]^{T}, \widehat{i}=\left[\begin{array}{llll}\widehat{i_{d p}} & \widehat{i_{q p}} & \widehat{i_{d s}} & \widehat{i_{q s}}\end{array}\right]^{T}$, are estimated currents, and $i=\left[\begin{array}{llll}i_{d p} & i_{q p} & i_{d s} & i_{q s}\end{array}\right]^{T}$, are measured currents. $K_{p}$ and $K_{s}$ are the constants observer gains. $\operatorname{sign}(\mathrm{S}(\mathrm{x}))$ is the sign function. With the intention of decreasing the chattering phenomenon, the $\operatorname{sign}(\mathrm{S}(\mathrm{x}))$ term is replaced by saturation function $\operatorname{Sat}(\mathrm{S}(\mathrm{x}))$, defined by [18]:

$$
\operatorname{Sat}(S)=\left\{\begin{array}{ccc}
1 & \text { if } & S>\gamma \\
S / \gamma & \text { if } & |S| \leq \gamma \\
-1 & \text { if } & S<\gamma
\end{array}\right.
$$

where $\gamma$ is a small positive constant. The SMO can be described by:

$$
\left\{\begin{array}{l}
L_{p} \frac{d \widehat{i_{d p}}}{d t}=-R \widehat{i_{d p}}+V_{d p}-K_{p} \operatorname{Sat}\left(S_{d p}\right) \\
L_{p} \frac{d \hat{i_{q p}}}{d t}=-R \widehat{i_{q p}}+V_{q p}-K_{p} \operatorname{Sat}\left(S_{q p}\right) \\
L_{s} \frac{d \overrightarrow{i_{d s}}}{d t}=-R \widehat{i_{d s}}+V_{d s}-K_{s} \operatorname{Sat}\left(S_{d s}\right) \\
L_{s} \frac{d \widehat{i_{q s}}}{d t}=-R \widehat{i_{q s}}+V_{q s}-K_{s} \operatorname{Sat}\left(S_{q s}\right)
\end{array}\right.
$$

In order to verify the stability of SMO, Lyapunov function is defined by [16]:

$$
V=\frac{1}{2} S(x)^{T} S(x)
$$

The stability condition of the SMO are:

- The Lyapunov function $\mathrm{V}$ is definite positive.

- The derivative of $\mathrm{V}$ is negative.

Taken in consideration the substantiate of the first condition, the second one is described by:

$$
\dot{V}=S(x)^{T} \dot{S}(x)<0
$$

The state error is given by:

$$
\left\{\begin{array}{l}
S_{d p}=\widehat{i_{d p}}-i_{d p} \\
S_{q p}=\widehat{i_{q p}}-i_{q p} \\
S_{d s}=\widehat{i_{d s}}-i_{d s} \\
S_{q s}=\widehat{i_{q s}}-i_{q s}
\end{array}\right.
$$


Using eq. (24) and (27), the dynamics of estimation error are expressed as follows:

$$
\left\{\begin{array}{l}
L_{p} \frac{d S_{d p}}{d t}=-R S_{d p}+e_{d p}-K_{p} \operatorname{Sat}\left(S_{d p}\right) \\
L_{p} \frac{d S_{q p}}{d t}=-R S_{q p}+e_{q p}-K_{p} \operatorname{Sat}\left(S_{q p}\right) \\
L_{s} \frac{d S_{d s}}{d t}=-R S_{d s}+e_{d s}-K_{s} \operatorname{Sat}\left(S_{d s}\right) \\
L_{s} \frac{d S_{q s}}{d t}=-R S_{q s}+e_{q s}-K_{s} \operatorname{Sat}\left(S_{q s}\right)
\end{array}\right.
$$

Taken into consideration that all states of PMSM are bounded, the sliding mode surface condition, $S(x)=0$ given by $S(x)^{T} \dot{S}(x)$ is satisfied with set defined by , [6], [16] :

$$
\left\{\begin{array}{l}
K_{p}>\max \left(\left|e_{d p}\right|,\left|e_{q p}\right|\right) \\
K_{s}>\max \left(\left|e_{d s}\right|,\left|e_{q s}\right|\right)
\end{array}\right.
$$

The stabilisation of SMO is obtained by an appropriate choice of $K_{p}$ and $K_{s}$, which is large enough.

One time the system reaching $S(x)$ :

$$
\dot{S}(x)=S(x)=0
$$

Substituting eq. 30 into eq. 28, we have:

$$
\left\{\begin{array}{l}
e_{d p}=K_{p} \operatorname{Sat}\left(\widehat{i_{d p}}-i_{d p}\right) \\
e_{q p}=K_{p} \operatorname{Sat}\left(\widehat{i_{q p}}-i_{q p}\right) \\
e_{d s}=K_{s} \operatorname{Sat}\left(\widehat{i_{d s}}-i_{d s}\right) \\
e_{q s}=K_{s} \operatorname{Sat}\left(\widehat{i_{q s}}-i_{q s}\right)
\end{array}\right.
$$

where $e_{d p}, e_{q p}, e_{d s}$ and $e_{q s}$ are the back EMF of PMSM.

\section{B. Position and rotor speed estimation}

Using estimated currents, we can deduce the estimation electromagnetic torque from the eq. 4 :

$$
\widehat{T_{e m}}=\sqrt{\frac{5}{2}}\left(k_{1} \widehat{i_{q p}}-k_{3} \widehat{i_{q s}}\right)
$$

Then the mechanical rotor speed can be calculated from the previous estimation of currents, electromagnetic torque and the back EMF by its expression:

$$
\widehat{\Omega}=\frac{\widehat{\vec{e}} * \widehat{\vec{i}}}{\widehat{T_{e m}}}
$$

More over, the evaluated value of rotor position can be directly calculated by simple derivative operation in the observer.

$$
\widehat{\theta}=n p \frac{d \widehat{\Omega}}{d t}
$$

The studied speed sensorless control is shown in Fig. 1.

It should be noted that the input parameters of SMO are currents and voltage signals which are defined using real measurements of the system, and estimated rotor speed and torque are the outputs.

\section{Simulation RESUlts}

For the purpose of verifying the validity and effectiveness of the sensorless control technique, the proposed system described in Fig. 1. has been implemented in the Matlab/Simulink platform, and tested under different operating conditions: load torque application, and inversion of speed, but first of all we have to check the robustness and the stability of the system in case of parametric variation. The main parameters of five phase PMSM are listed in Tab.I

\section{A. Simulation results with / without parametric variation}

During operation of PMSM, its parameters are subject to variations that may be due to saturation or heating. For example, the stator resistance varies when the temperature of the winding increases following an application of the load. With the aim of verifying the performance of developed observer, it's important to study the influence of parameter variation on the machine operation; we thus carried out tests of robustness in order to analyze the different transient and permanent performances, as well as that of the observer.

1) Stator resistance variation: Fig. 2 shows speed and torque variation in healthy case, and with parametric variation. The estimated speed and torque follow track rapidly its reference trajectory as shown in Fig. 2 (a) and (c) . Considering the resistance variation at around $+100 \%$, Fig. 2 (a) and Fig. 2(c) show that an error of $+100 \%$ of the stator resistance rating slightly affects the dynamic and static performance of the SMO during the transient regime in case of speed variation, with an average error less than $2 \%$, as shown in Fig. 2 (b) and (d)

2) Stator inductance variation: Considering the inductance variation at around $-70 \%$, Fig 3 (a), (b), (c) and (d) illustrate the low parametric sensitivity of the observer with the variation of the stator inductance. Indeed, this low sensitivity can result in a sufficient robustness of the observer compared to a possible saturation of the magnetic circuit. It's clear that the estimated parameters coincide with the reference values in both of transient and steady state, which is making the error converge to zero. Hence the SMO preserved its good performances and high robustness against the parametric variation.

\section{B. Simulation results under NYCC driving cycles}

Now, to examine the performance of the observer, in more large speed transition from low until rated value, we use the New York City Cycle "NYCC" which represents an urban route through New York. Fig.4 shows the estimated performance of PMSM under the NYCC. This drive cycle is characterized by its low average speed.

It can be observed in Fig.4 (a) that the estimated speed follow track rapidly their reference value with an average speed estimation error approximately equal to zero, which confirms the effectiveness of the SMO, as shown in Fig.4(b). The estimated electromagnetic torque follows perfectly the load torque generated by the machine in all of the speed range, as shown in Fig.4(c) and (d) It's noticed that the varying 


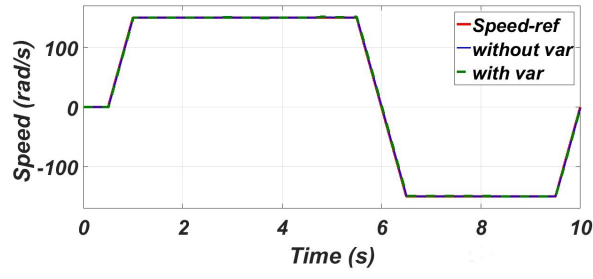

(a)

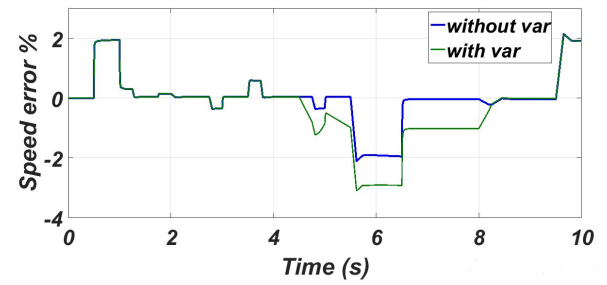

(b)

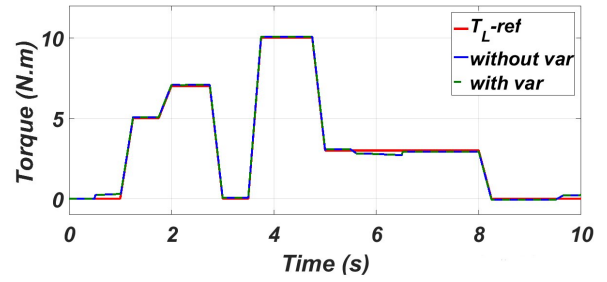

(c)

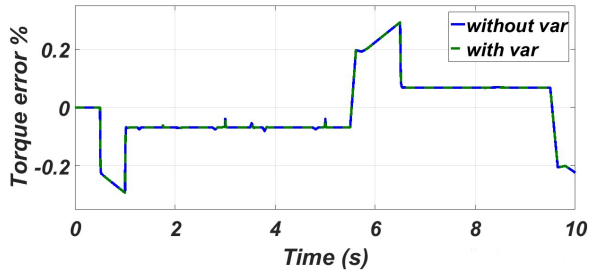

(d)

Fig. 2. Speed and torque estimation with parametric variation $+100 \%$ on $\mathrm{R}$

parameters and the disturbances do not have any significant effects on PMSM performance or the observer estimation. It can be deduced that the SMC and SMO work under large range speed conditions with the presence of disturbances and varying parameters.

\section{CONCLUSION}

In this work, SMO based sensorlless control is developed to drive a multi-phase PMSM. The proposed technique establish the SMO. The controller is associated with the SMO, and stability conditions are proved using Lyapunov function under large range of speeds. The obtained results prove the effectiveness of the SMC with a SMO in terms of speed tracking, load disturbances rejection and with parametric variation.

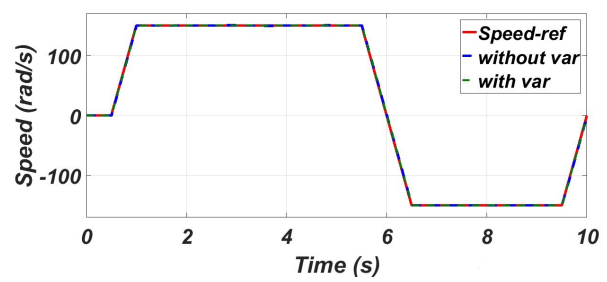

(a)

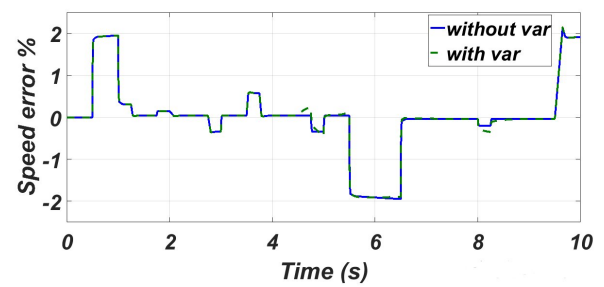

(b)

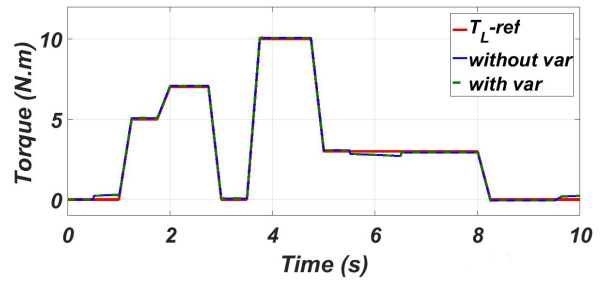

(c)

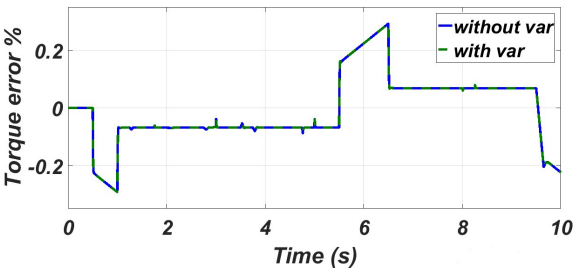

(d)

Fig. 3. Speed and torque estimation with parametric variation $-70 \%$ on $L_{p}$ and $L_{s}$

TABLE I

PARAMETERS OF FIVE-PHASE PMSM

\begin{tabular}{|c|c|c|}
\hline Parameter & Label & Value \\
\hline Number of pole pairs & $n_{p}$ & 2 \\
\hline PMSM phase resistance & $R$ & $5 \Omega$ \\
\hline Principal motor inductance & $L_{p}$ & $0.1228 \mathrm{H}$ \\
\hline Seconder motor inductance & $L_{s}$ & $0.0222 \mathrm{H}$ \\
\hline Inertia moment & $J$ & $0.00075 \mathrm{Kg} . \mathrm{m}^{2}$ \\
\hline Viscous friction coef ficient & $f$ & $0.000457 \mathrm{~N} . \mathrm{m} . \mathrm{s} / \mathrm{rad}$ \\
\hline
\end{tabular}

\section{APPENDIX}




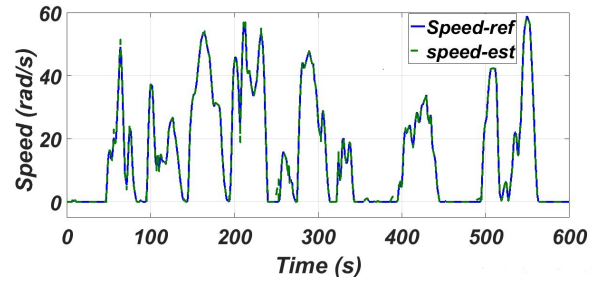

(a)

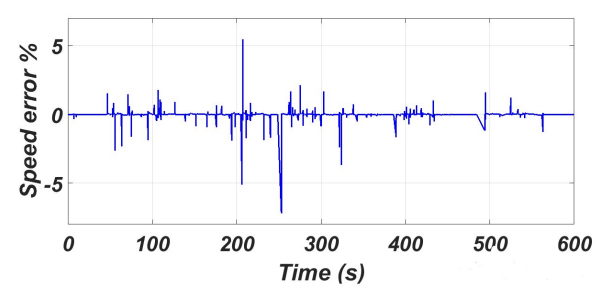

(b)

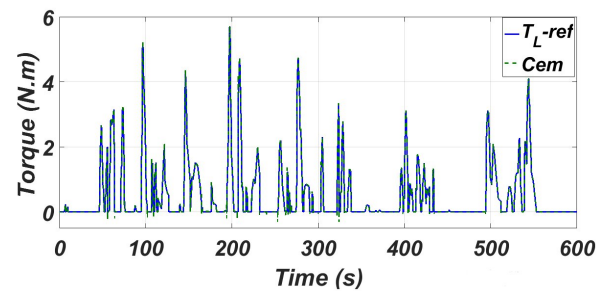

(c)

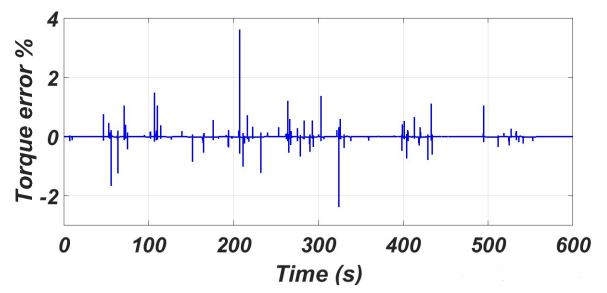

(d)

Fig. 4. Estimated speed and torque of PMSM under NYCC drive cycle

\section{ACKNOWLEDGMENT}

This work was supported by the Ministry of the Higher Education and Scientific Research in Tunisia.

\section{REFERENCES}

[1] A. Mohammadpour and L. Parsa, "A unified fault-tolerant current control approach for five-phase pm motors with trapezoidal back emf under different stator winding connections," IEEE Transactions on Power Electronics, vol. 28, no. 7, pp. 3517-3527, 2013.

[2] A. Hezzi, S. B. Elghali, Y. B. Salem, and M. N. Abdelkrim, "Control of five-phase pmsm for electric vehicle application," in Sciences and Techniques of Automatic Control and Computer Engineering (STA), 2017 18th International Conference on. IEEE, 2017, pp. 205-211.

[3] F. Mekri, J.-F. Charpentier, and E. Semail, "An efficient control of a series connected two-synchronous motor 5-phase with non sinusoidal emf supplied by a single 5-leg vsi: Experimental and theoretical investigations," Electric Power Systems Research, vol. 92, pp. 11-19, 2012.

[4] M. Bermudez, I. Gonzalez-Prieto, F. Barrero, H. Guzman, X. Kestelyn, and M. J. Duran, "An experimental assessment of open-phase faulttolerant virtual-vector-based direct torque control in five-phase induction motor drives," IEEE Transactions on Power Electronics, vol. 33, no. 3, pp. $2774-2784,2018$
[5] I.-K. Won, J.-H. Hwang, D.-Y. Kim, Y.-H. Jang, and C.-Y. Won, "Performance improvement of ipmsm using finite predictive current control for ev," in Future Energy Electronics Conference (IFEEC), 2015 IEEE 2nd International. IEEE, 2015, pp. 1-7.

[6] H. Kim, J. Son, and J. Lee, "A high-speed sliding-mode observer for the sensorless speed control of a pmsm," IEEE Transactions on Industrial Electronics, vol. 58, no. 9, pp. 4069-4077, 2011.

[7] M. R. Khan and A. Iqbal, "Extended kalman filter based speeds estimation of series-connected five-phase two-motor drive system," Simulation Modelling Practice and Theory, vol. 17, no. 7, pp. 1346-1360, 2009.

[8] L. Meyer, D. Ichalal, and V. Vigneron, "Interval observer for lpv systems with unknown inputs," IET Control Theory \& Applications, 2017.

[9] W. Kong, J. Huang, B. Li, M. Kang, and L. Zhao, "Improved slidingmode observer for sensorless control of five-phase induction motor," in 2013 International Conference on Electrical Machines and Systems (ICEMS). IEEE, 2013, pp. 2024-2027.

[10] A. Ammar, A. Bourek, and A. Benakcha, "Robust load angle direct torque control with svm for sensorless induction motor using sliding mode controller and observer," International Journal of Computer Aided Engineering and Technology, vol. 11, no. 1, pp. 14-34, 2019.

[11] W. Lu, Z. Zhang, D. Wang, K. Lu, D. Wu, K. Ji, and L. Guo, "A new load torque identification sliding mode observer for permanent magnet synchronous machine drive system," IEEE Transactions on Power Electronics, 2018

[12] A. Haddoun, M. E. H. Benbouzid, D. Diallo, R. Abdessemed, J. Ghouili, and K. Srairi, "A loss-minimization dtc scheme for ev induction motors," IEEE Transactions on Vehicular Technology, vol. 56, no. 1, pp. 81-88, 2007.

[13] L. Guo and L. Parsa, "Torque ripple reduction of the modular interior permanent magnet machines using optimum current profiling technique," in 2009 IEEE International Electric Machines and Drives Conference. IEEE, 2009, pp. 1094-1099.

[14] J.-J. E. Slotine, W. Li et al., Applied nonlinear control. Prentice hall Englewood Cliffs, NJ, 1991, vol. 199, no. 1.

[15] N. Bounasla, S. Barkat, E. Benyoussef, and K. Tounsi, "Sensorless sliding mode control of a five-phase pmsm using extended kalman filter," in 2016 8th International Conference on Modelling, Identification and Control (ICMIC). IEEE, 2016, pp. 97-102.

[16] Z. Qiao, T. Shi, Y. Wang, Y. Yan, C. Xia, and X. He, "New slidingmode observer for position sensorless control of permanent-magnet synchronous motor," IEEE Transactions on Industrial electronics, vol. 60, no. 2 , pp. $710-719,2013$

[17] M. Okte et al., "Sliding-mode observer for estimating position and speed and minimizing ripples in rotor parameters of pmsm," in 2018 2nd International Conference on Inventive Systems and Control (ICISC). IEEE, 2018, pp. 506-511.

[18] R. Trabelsi, A. Khedher, M. F. Mimouni, and F. M'sahli, "Backstepping control for an induction motor using an adaptive sliding rotor-flux observer," Electric Power Systems Research, vol. 93, pp. 1-15, 2012. 